\title{
MITOLOGIAS MIDIÁTICAS DE PELÉ, RONALDINHO GAÚCHO E NEYMAR JR. ANÁLISE SEMIÓTICO-DISCURSIVA DAS HQS DE MAURÍCIO DE SOUSA
}

\author{
MYTHOLOGIES MEDIA OF PELÉ, RONALDINHO GAUCHO AND NEYMAR JR. \\ SEMIOTIC-DISCURSIVE ANALYSIS OF MAURICIO DE SOUSA'S COMICS
}

Fábio de Carvalho Messa ${ }^{1}$

Resumo

\begin{abstract}
Este artigo apresenta e discute os perfis de três personagens-títulos das histórias em quadrinhos da Turma da Mônica, de Maurício de Sousa - Pelezinho, Ronaldinho Gaúcho e Neymar Jr., craques do futebol brasileiro - para evidenciar as diferentes formas de representação simbólica do futebol no imaginário midiático. A partir de um trabalho metodológico de monitoramento semiótico-discursivo das edições impressas de fevereiro de 2013 a fevereiro de 2014, selecionaram-se algumas passagens para destacar as distintas nuances do conhecimento sobre o futebol veiculado nas narrativas, por meio de determinadas ocorrências sígnicas. São elas: características das personalidades dos heróis (sujeitos históricos) e suas bases parafrásticas e paródicas; figuratividades do futebol - presença da bola, aspectos sociais e pedagógicos do desporto, propaganda ideológica, estereótipos e índices morais e políticos subjacentes às narrativas. Com base nessa categorização e nas teorias da linguagem de Roland Barthes e Umberto Eco, identificamos que a revista do Pelezinho, proposta mais antiga do autor, concentra no personagem grande parte do repertório cultural do futebol brasileiro dos anos 70-80, condensando questões de linguagem e comportamento, assim como a disseminação dos saberes sobre o futebol e sua pedagogia, incluindo seus desdobramentos afetivos e sociais. Já as histórias de Ronaldinho Gaúcho e Neymar Jr. têm suas propostas encomendadas a partir de temas recorrentes da agenda midiática nacional dos anos 2000, com um menor comprometimento com os saberes acerca do futebol. Por meio de enredos pouco problematizáveis, as políticas editoriais dessas duas últimas tematizam amenidades do universo infantil, engrenam campanhas ideológicas, que reforçam estereótipos e padrões morais, geralmente extraídos da factualidade jornalística e/ou da mitologia midiático-esportiva brasileira.
\end{abstract}

Palavras-chaves: Futebol; História em Quadrinhos; Semiótica; Mito; Metáfora.

\section{Abstract}

\begin{abstract}
This article presents and discusses the profiles of three characters-titles of comics Monica's Gang, Maurício de Sousa - Pelezinho, Ronaldinho and Neymar Jr., stars of Brazilian football - to highlight the different forms of symbolic representation of football in media imagery. From a methodological work of semiotic-discursive monitoring of printed editions from February 2013 to February 2014, we selected some passages to highlight the distinct nuances of knowledge about football in the narratives conveyed through certain signical occurrences. They are: Personality characteristics of heroes (historical subjects) and its parodic paraphrastics bases; figurativities football - the presence of the ball, social and educational aspects of sport, ideological advertising, stereotypes and narratives underlying moral and political indices. Based on this categorization and the theories of Roland Barthes and Umberto Eco language, we identified that the magazine Pelezinho, older proposal of the author, focuses on the character much of the cultural repertoire of Brazilian football of 70-80 years, condensing language issues and behavior, as well as the dissemination of knowledge about soccer and its pedagogy, including their emotional and social consequences. Have the stories of Ronaldinho and Neymar Jr. have their proposals ordered from recurring themes of the national media agenda of the 2000s, with a smaller commitment to knowledge about football. Through problematics little plots, the editorial policies of these last two thematize amenities of childhood, engage ideological campaigns that reinforce stereotypes and moral standards, usually extracted from the journalistic factuality and / or the Brazilian media-sports mythology.
\end{abstract}

Keywords: Football; Comics; Semiotics; Myth; Metaphor.

Fecha de recepción: 15 de julio de 2014

Fecha de aprobación: 21 de noviembre de 2014

1 Universidade Federal Do Paraná. Correo electrónico: fabiomessa@ufpr.br 
Para citar este artículo:

Messa, F. (2014). Mitologias midiáticas de Pelé, Ronaldinho Gaúcho e Neymar jr. Análise semiótico-discursiva das hqs de Maurício de Sousa. Revista Lúdica Pedagógica, (20), 37-46.

Sabe-se que as histórias em quadrinhos (HQs) são textos que transitam entre os gêneros literários e midiáticos, pois são produtos de massa que contém narrativas criativas que tangenciam os gêneros jornalísticos e publicitários, além de convergirem nelas outros códigos culturais que são o das imagens iconográficas, com notações léxicas e técnicas próprias, circunscritas por conteúdos diversificados do entretenimento - ideologias e elementos culturais heterogêneos. Elas são instigante veículo de mensagens ideológicas e de crítica social.

Esse estigma de subproduto de cultura que carregam as HQs se constitui em função da estrutura industrial de grande escala, envolvendo interesses econômicos que podem até mesmo comprometer sua relação mais dinâmica com a cultura.(Bibe-Luyten, 1985) Há forte influência que os quadrinhos exercem em seus leitores, independente da faixa etária e também da modalidade - graphic novel, comic strips etc. Muitos escritores, roteiristas e cineastas se inspiraram nas HQs para a confecção de suas obras. Hoje vivemos o boom das adaptações cinematográficas da dinastia Marvel em diferentes propostas e consignações.

Tentando, sinteticamente, conceituar gêneros textuais, retomam-se as palavras de Marcuschi (2003) que dizia que:

são fenômenos históricos, profundamente vinculados à vida cultural e social. Fruto de trabalho coletivo, os gêneros contribuem para ordenar e estabilizar as atividades comunicativas do dia-a-dia. São entidades sócio-discursivas e formas de ação social incontornável em qualquer situação comunicativa. No entanto, mesmo apresentando alto poder preditivo e interpretativo das ações humanas em qualquer contexto discursivo, os gêneros não são instrumentos estanques enrijecedores da ação criativa. Caracterizam-se como eventos textuais altamente maleáveis, dinâmicos e plásticos. Surgem emparelhados a necessidade e atividades sócio-culturais, bem como na relação com inovações tecnológicas, o que é facilmente perceptível ao se considerar à quantidade de textuais hoje existentes em relação a sociedades anteriores à comunicação escrita. Usamos a expressão gênero textual para nos referirmos a textos materializados que encontramos em nossa vida diária. Marcuschi (p. 2003)
0 gênero textual não designa apenas um tipo particular de texto, materializado tecnicamente de uma forma, mas também as suas condições particulares de produção, distribuição e também de consumo. Assim, considerando as HQs não só como gênero discursivo, mas antes disso um gênero textual, parece viável constatar e discutir, como já fizeram diversos pesquisadores, que o texto das HQs ocorre num determinado contexto (veículo impresso ou eletrônico, para uma determinada comunidade leitora), envolvendo distintos agentes (relações texto-leitor), que produzem e consomem, lêem e interpretam.

Convém ressaltar que as HQs têm grande valor como texto, pois se definem pelo uso híbrido da linguagem (verbal e não-verbal). Suas formas de percepção se materializam por meio da escrita e do desenho, sendo a síntese olho-ouvido resultante o vestígio que testemunha e registra a concorrência de signos sociolingüísticos, culturais, ideológicos, psicológicos presentes a um só tempo nesse tipo de produto cultural. 0 componente lingüístico é co-responsável, juntamente com os componentes gráfico e imagético, pelo grau de informatividade e poder argumentativo, persuasivo da mensagem. (Trevisan,1992)

Vê-se que a autora fala em componentes lingüísticos, gráficos e imagéticos, exemplifica com charges, mas estendemos obviamente para o vislumbramento das HQs. Em cima disso, poder-se-ia pensar que todos esses componentes consistem num só, que é o componente textual e que, após a leitura da narrativa, o leitor tem condições de depreender um outro componente, que é o seu componente retórico, isto é, o seu intento, sua ideologia subjacente.

O todo das HQs consiste numa mistura de diversos elementos que contribuem para formar um conjunto ainda maior de sentidos, intenções e crenças, permitindo ao leitor captar a trama do encontro entre o pensamento popular e os vários dizeres, falares e pensares que existem na sociedade.

As HQs, como texto de massa, para consumo imediato em forma de tirinhas nos veículos impressos e eletrônicos, também se instituem dentro de uma rede de saberes já compartilhada entre autores e leitores. A interação das HQs com o leitor ocorre por meio de um processo que é imposto à recepção, a partir de determinadas informações já conhecidas de ambos os lados. Há uma quantidade significativa, também, de produção científica no campo das letras, principalmente, que 
trata do uso das HQs na sala de aula, essencialmente no ensino de língua portuguesa, relacionando-as com questões referentes à formação de jovens leitores.

Para ilustrar esse fenômeno, nada mais conveniente do que pensar em histórias que têm como eixo personagens que tematizam o esporte, como é o caso das revistas do Pelezinho, Ronaldinho Gaúcho (RG) e Neymar $J r$.(NJ) que, ao referirem-se ao futebol, recupera um arsenal de elementos que já fazem parte do cotidiano e do repertório cultural de seus leitores, que são as representações que cada um desses sujeitos-personagens-históricos do futebol brasileiro têm no universo midiático, e que ali constam caricaturizados (parafraseados ou parodiados).

O pioneiro nessa empreitada de Maurício de Sousa em querer perfilar personagens a partir de jogadores de futebol, foi o projeto Pelezinho, em comum acordo com o próprio Pelé, que tinha inclusive uma participação nas edições, como a de responder cartas de leitores, assim como interagir em processos dialógicos com os personagens das histórias. Tudo começou em 1976, quando a personagem estreou em tiras de jornais, ganhando sua própria revista um ano depois. Foram cerca de 58 edições que Pelezinho e uma turma peculiar de amigos conquistou o público, cada um dos componentes do grupo tinha uma especificidade cultural e ideológica sobre o mundo do futebol.

Nas tirinhas de jornais, já se percebia o tom irônico e divertido do discurso de Pelezinho. Mas foi nas histórias seguintes que sua turma começou a ser apresentada. Em agosto de 2012, as edições históricas foram relançadas e continuam circulando até hoje mensalmente. Na edição de número um, original de agosto de 1977, em Lançando no Campo, o leitor já pôde conhecer os quibes duros que Samira fazia para alimentar os amigos jogadores, assim como o cachorro Rex também tinha suas habilidades futebolísticas. No texto Briguinhas, é Cana Brava que surge expondo seu repertório vocabular chulo, uma de suas marcas registradas, falar palavrões em grande quantidade, além de ser intolerante nos jogos.

Outra característica singular à revista Pelezinho era a proposta de passatempos, sempre envolvendo questões sobre o mundo do futebol e informações sobre a pedagogia do desporto. Nas histórias Rola, rolando e $O$ Inimigo Número Um, mostram situações que se tornaram habituais nas aventuras de Pelezinho, que são os possíveis antagonistas querendo conspirar contra as habi- lidades do herói, assim como tirá-lo dos jogos a partir de sabotagens. Surge, portanto, um dos seus principais inimigos, o Jão Balão.

Na história que abre a edição número dois de Pelezinho, Um Colega de Infância, mostra Pelezinho, Dona Maricota e Cana Brava reagindo a um assalto, usando habilidades futebolísticas. Dondinho, o pai de Pelezinho, também é apresentado na história pela primeira vez. E assim, os personagens vão surgindo e formando o elenco da revista. Geralmente os conflitos de cada narrativa giram em torno de razões triviais sempre ligadas ao futebol, que servem para ilustrar as corriqueiras brigas entre as crianças nas relações de poder em torno dos brinquedos e brincadeiras. A característica mais marcante de Pelezinho é a potência e a força de seu chute, semelhante ao poder do coelho Sansão da Mônica. Eram estes mesmos superchutes que se encarregavam de salvar os personagens nas mais diversas situações. 0 superchute era a arma de Pelezinho. Muitas atitudes de Pelezinho seriam hoje consideradas politicamente incorretas como a de chutar e cabecear um dentista, de quem o herói tinha medo e pavor em visitá-lo.

Na edição número três, de outubro de 1977, Olho na Jogada mexe com uma história que ficou conhecida em 1970, quando se divulgou que João Saldanha, então técnico da seleção brasileira, teria comentado que Pelé enxergava mal à noite, asserção que posteriormente teria sido desmentida pelo próprio jogador. Isso bastou para a imprensa se revoltar contra o técnico, o que acarretou na sua substituição por Zagalo, que foi quem efetivamente dirigiu a equipe na Copa do México. Na história, existe uma espécie de 'plano infalível' contra Pelezinho. E é Jão Balão que assume o papel do Cebolinha, cabendo ao Zé o lugar do Cascão, em estragar tudo, algo que se repetiu em edições posteriores.

Constata-se que é não somente privilégio das histórias de Pelezinho, mas a de Ronaldinho Gaúcho (RG) e Neymar Jr. (NJ), a ocorrência de intertextos do mundo jornalístico factual. A intertextualidade "compreende as diversas maneiras pelas quais à produção e recepção de dado texto depende do conhecimento de outros textos por parte dos interlocutores, isto é, diz respeito aos fatores que tornam a utilização de um texto dependente de um ou mais textos previamente existentes, pois existe um diálogo entre textos" (KOCH, 1999, p.88). Então as HQs, que são de natureza gráfica, também apresentam alguns destes critérios firmados para textos verbais, dentre eles, a interdiscursividade, por estabelecer relações entre o texto-base e outros textos produzidos. 
E como os heróis são todos já extraídos do universo narrativo midiático sobre o futebol brasileiro, nada mais previsível de que surjam diversos elementos temáticos da factualidade jornalística, até pra mostrar que não só é entretenimento, mas que pode veicular informações, repassar asserções, além de promover a mitificação dos personagens sujeitos-históricos.

Considera-se aqui que o mito é uma fala, uma narrativa, um discurso que se constrói, tendo como objeto um fenômeno qualquer, um sujeito, um ato, um acontecimento. 0 mito é matéria-prima da mente, domina todas as construções dos homens, seja nas histórias, nas formas de organização social, política e religiosa.

É Barthes (2001) quem concebe mito como narrativa de uma criação, uma história que conta de que modo algo, que não era, começou a ser. De outro lado, o mito é sempre uma representação coletiva, transmitida através de várias gerações e que relata uma explicação de mundo. E, desse modo, se o mito pode se exprimir ao nível da linguagem, é, antes de tudo, uma palavra que circunscreve e fixa um acontecimento. É sentido e vivido antes de ser inteligível e formulado.

O inusitado na obra de Barthes reside propriamente no estilo de seu texto. $\mathrm{O}$ autor faz um ensaísmo semiológico sobre a cultura de consumo, principalmente sobre os códigos culturais midiatizados. Em função disso nomeia Mitologia como o movimento desse material: algo de estável e mutável simultaneamente, sujeito, portanto, a transformações.

Do ponto de vista etimológico, mitologia é o estudo dos mitos, concebidos como história verdadeira. Sendo o mito uma fala, é um sistema de comunicação, uma mensagem. Um sistema semiológico. 0 fato é que tais imperativos levam seus leitores a um pensamento generalizante de que tudo pode ser mito. 0 autor responde que sim, pois o universo é infinitamente sugestivo. Tudo pode constituir mito, desde que seja suscetível de ser julgado por um discurso.

Nenhuma lei, natural ou não, pode impedir os sujeitos de falar das coisas, pois já se vive num mundo repleto de objetos, coisas, gestos e imagens que significam e ressignificam. 0 mito se acrescenta à matéria através do uso social que se faz dela. 0 tempo influencia as manifestações míticas, e é a história quem transforma o real em discurso.

Para se perpetuar, o mito pode ter como suporte o discurso escrito, a fotografia, o cinema, a reportagem, os espetáculos, a publicidade e, portanto, o esporte. A matéria-prima do mito, seja a escrita ou a imagem, pos- sui significação. Para fazer um estudo sistematizado do mito, é preciso atrelar-se a uma ciência geral da linguagem, que é a Semiologia.

Embora todos esses fatores possam ser identificados e discutidos em textos híbridos, como as HQs, o que mais se evidencia, em termos de reflexões teóricas de cunho acadêmico é a intertextualidade, já que se refere aos aspectos que tornam a utilização de um texto (produção e recepção) dependente de outro(s) texto(s) previamente existente(s).

Assim, expande-se a concepção de intertextualidade, já que o fenômeno pressupõe um universo cultural amplo e complexo, implicando na identificação ou reconhecimento de remissões a obras ou a textos / trechos relativamente conhecidos. Então o fenômeno ocorrerá de forma implícita, sempre quando não vier citada diretamente da fonte, fazendo o leitor recuperá-la num exercício de paráfrase. Pode também ocorrer explicitamente, quando houvera referência da fonte do intertexto.

Isso gera a constatação, portanto, de que todo texto é um intertexto, pois outros textos sempre estarão presentes nele, em diversos níveis. E o discurso das HQs fica assim estabelecido como uma trama que se dirige a determinados sujeitos socialmente situados, já inscritos em uma dada ideologia, pois só na medida em que o são é que se tornam receptores capazes de decodificar as referências ativadas e cooperar na sua construção de sentido.

Mesmo que as HQs sobre personagens históricos do futebol brasileiro sejam destinadas a um tipo de leitor, que já é um leitor infantil, em sua maioria já um pequeno torcedor, que já tem internalizado um repertório mínimo, capaz de leva-lo à interpretação pretendida pelo emissor, a sua leitura será sempre diferente para cada um, já que cada sujeito cria um contexto, constituindo-o e interpretando-o, à medida que o conhecimento vai se articulando ao que está arquivado no plano da memória.

As primeiras aparições de Ronaldinho Gaucho (RG) ocorreram em edições convencionais da Turma da Mônica, em 2006. Sua primeira edição como protagonista independente surgiu em janeiro de 2007. De lá ate hoje, já existem 90 edições. Na edição número um, já se percebe algumas peculiaridades de forma e conteúdo. Ronaldinho, por ser 'gaúcho', já incorpora um pouco do linguajar e dos falares regionais urbanos correspondentes ao estado. Expressões como 'bah', 'tri-legal', 'tchê' e 'capaz' surgem forçosamente nas primeiras historinhas, 
e vão sendo esquecidas conforme a sequencia das edições. A primeira história Gol na Trave problematiza os seguintes aspectos: a preocupação das crianças com a construção de um campinho de futebol para jogarem, o entrosamento dos componentes dos grupos nos jogos, as lições de Ronaldinho aos demais colegas como a oficina de construção de traves de gol, a não-ocorrência do jogo por causa da chuva e a criatividade para construírem traves com cabana de proteção. Percebe-se que Ronaldinho vive em constante desejo por jogar bola, independente do contexto em que esteja inserido. Nas primeiras histórias, a personagem interage mais com os outros personagens protagonistas de Maurício de Sousa como Cebolinha e Cascão, mas isso também passa a ser esquecido, no momento em que as narrativas emplacam e passam apenas a mostrar o universo da família de Ronaldinho e os novos integrantes dessa turma como Diego, sua irmã Deise, seu irmão Assis.

Já na segunda história Indo atrás do Sonho, a família de Ronaldinho é apresentada, sua mãe e seus irmãos Assis e Deise. Problematiza-se o início da carreira do jogador, quando ele precisa jogar fora de sua cidade, no interior do país ou no exterior, para garantir-se no mercado de trabalho.

Na terceira história Boca Suja tematiza-se a ocorrência de um jogo, no qual os irmãos jogam juntos e a linguagem obcena e chula dos torcedores com xingamentos são enfatizadas a partir do espanto da menina Deise. Sabe-se que existe uma padronização de especificação dos xingamentos nas HQs, representadas pelos seguintes signos: caveira, crânio, tachinhas, pregos, nuvem escura, bomba, raios, cobras, sinais gráficos e exclamações diversas. Deise está na arquibancada e se horroriza com o excesso de palavrões proferidos pela torcida. A garota julga essas atitudes e tenta moralizar. Todos reagem, oprimindo-a, dispondo os xingamentos com novas representações gráficas como ossos cruzados, círculos espirais, estrelas arredondadas, salamandras, lagartixas, punho em soco. Chega o momento que Deise percebe que até o juiz xinga o jogador e vice-versa. E.a mesma se surpreende à tentação de também xingar o juiz junto à torcida. Quando ela resolve soltar as palavras contidas, saem de sua boca termos muito mais amenos como 'bobalhão', 'chato de galocha'. Todos estes termos realmente algum dia já pronunciados, mas geralmente por crianças, pois seriam termos menos abusivos a questões escatológicas e obcenas. De repente todos percebem a leveza de suas palavras e acabam zombando dela. Até o seu próprio irmão RG e o juiz riem dela. Como se o estranhamento dela sobre os ritos dos freqüentadores dos estádios e das equipes gerasse, portanto, o grande estranhamento.

A história A Bola que deu Bolo mostra a constante vontade, pra não dizer quase obsessão, idéia fixa, de RG em querer jogar e bater bola o tempo todo. Ele usa até os ursos de pelúcia e as bonecas da irmã como jogadores, anima o que é inanimado a servir de obstáculos físicos e interlocutivos. Entra em conflito com a irmã, quando dá uma bolada na sua boneca e decepa-lhe a cabeça. A lição de Deise ao irmão é a de que nem todo lugar é lugar para jogar bola.

Na história É a Dona Miguelina, RG interage com Cascão e outros amigos da turma da Monica. Dona Miguelina é a mãe de RG. Para evidenciar que RG fala um sotaque com expressões estranhas, Cascão o tempo todo zomba alegando tradução. E assim, a obsessão de RG por bater bola vai se estendendo a outros contextos, quando ele treina um cão para jogar, quando confunde a bola com um extraterrestre, interage com Anjinho. Apresenta posteriormente o seu amigo Diego, em Personalidade Magnética. Contextualiza a situação de jogo, quando o gandula se confunde e quer jogar junto. Diego procura Franjinha para tornar-se um novo RG, mas Franjinha dá uma bola e um par de chuteiras magnéticos controlados por um dispositivos de radiotransmissão. Diego quer aprender a ser craque e a bola se desgoverna. No fim do conflito, RG deixa uma nova lição ao amigo: desvela-se do egoísmo e admite que o importante é brincar e se divertir. E que o futebol pode ser uma atividade integradora, não somente para que se faça gol e ganhe.

Em contraste com a primeira edição, propositadamente, comentamos a edição de numero 89, de maio de 2014 para percebermos as similitudes, aproximações e discrepâncias das abordagens e dos temas. Na história Conversando a gente se entende, problematiza-se o conflito entre Diego e RG devido ao cometimento de falta no jogo. A mãe de RG intercede, na tentativa de resolver a situação. Ela pega a bola, prende o jogo, e RG admite que cometeu a falta. Diego pondera que são 'coisas do futebol' e assim fazem as pazes. Verifica-se a polemização das relações entre as crianças amigas no jogo e as desavenças, a amizade e as relações de poder, com picardias e peraltices. Numa segunda circunstância, após as crianças terem recuperado a bola, promovem nova ocorrência acidental de quebrar e sujar a casa do vizinho. Este último surge, começam a discutir os adultos, acusadores e defensores, o vizinho condenando os dois jogadores, e a mãe defendendo RG. Logo as crianças 
constatam: 'adulto é tudo igual, brigam, brigam e depois se entendem'. A lição foi mútua. Na história Cachorradas Domésticas, RG entra em conflito com os seus dois cães, Bala e Bola, quando estes extraviam chuteiras e outros objetos. Uma história altamente de costumes que cria identificação imediata com os leitores que possuem animais domésticos

Já Neymar Jr, na primeira edição, de maio de 2013, abre com a história Garoto de Talento, desenvolve uma verdadeira teoria de que o talento está nos pés. Apresenta o pai de Neymar Jr., que o ensina a dividir o jogo com os colegas, sendo menos egoísta e individualista. Surge também a mãe de Neymar, Dona Nadine, sua irmã Rafaela (Rafa), que tem mania de ser repórter e costuma mimetizar as práticas comunicativas da Aldeia Global. Em Show de Talento, Neymar tem um coelho doméstico de nome Coelho, na história se problematiza a questão das crianças não arrumarem seus quartos. E mostra os talentos de Neymar surfar. Enfatiza a herança cultural dos talentos, de pai para filho.

Na história Hoje tem Campeonato, Neymar entra em conflito com a ocorrência de um campeonato de surf, numa disputa por espaço na praia. Mostra as atividades de frescobol, pipa e natação. Usa as taças de campeão para criar as traves do gol.. Na história É rapidinho, Neymar assiste televisão e no intervalo vai levar a irmã Rafa num concurso de bonecas Barbie. Em Chutou, quebrou, problematiza-se, assim como em RG, o onde jogar? Há um pôster (intertexto) do Pelezinho na sala de Neymar. Ele joga com o Coelho (assim como RG com os bichos de pelúcia e animais domésticos) e também quebra objetos na sala. Não encontra lugar para jogar bola. Na história Bichos, ele interage com animais, e até os animais o taxam de 'fominha'.

Voltando a RG número quatro, na história Ídolos da Nova Geração, tematiza a decepção da torcida ao descobrir que seus ídolos, entre eles RG, freqüentam salão de beleza. Cogita a polêmica em torno da metrossexualidade e do machismo. A história Cartões é curta e não verbal, apenas com onomatopéias e outros signos que evidenciam vivências corriqueiras sobre a falta no jogo e as relações simbólicas com os cartões. Mimetiza o cotidiano do futebol e condena a agressão verbal. Em Mais Longe mostra as diferenças de habilidades entre o chute e o arremesso/lançamento de avião de papel. RG mostra sua dificuldade nessa habilidade mais fina. E Cascão e Cebolinha demonstram melhor sensibilidade e destreza. RG subverte a regra e transforma o avião em bola de papel.
Em Devolvendo a Bola, há diversas ocasiões em que RG devolve a bola e os diferentes tipos de bola para diferentes circunstâncias de jogos alheios, até chutar uma bola de pedra e sentir dor. Já Noite Assombrada mostra o medo de filmes de terror e o investimento semiótico na construção da imaginação de RG, sugestionado pelos filmes, principalmente na construção do discurso onírico, e os processos de condensação (metaforização) e/ ou deslocamento (metonimização) no sonho.

Há um interesse aqui pela Retórica, devido à necessidade de caracterização de algumas das principais figuras de linguagem para identificação nas personagens das HQs, assim como aparecimento da discussão da problemática do discurso, impulsionada pela semiótica. Greimas \& Courtés (2008) estabelecem que:

A tomada de discussão em consideração do discurso como um todo, o reconhecimento das 'partes do discurso' e de sua organização sintagmática ('dispositio') correspondem a nossas preocupações com a segmentação e com a definição de unidades discursivas (mais amplas do que a frase). Todavia, definida desde a origem uma 'arte de bem falar', como uma 'arte de persuadir', não concerne à retórica senão uma classe de discursos, a dos discursos persuasivos. Por outro lado, dado que ela se deu por tarefa elaborar 'regras de arte', comporta um caráter normativo pronunciado.

Os elementos básicos dos estudos retóricos, de base aristotélica, são utilizados até hoje, nas pesquisas do discurso midiático, principalmente no que se refere ao texto publicitário, já que, por excelência, é a redação publicitária que investe legitimamente nas técnicas de persuasão e nas figuras de linguagem.

Hoje, já se ouve falar em Nova Retórica, que nada mais é do que uma revisão de conceitos de Aristóteles, feita por Chaim Perelman, em seu Tratado sobre a Argumentação (1966). Mas é na Estrutura Ausente (1971) que Umberto Eco retoma essas questões entre antiga e nova retórica, distinguindo pelo menos três sentidos distintos:

1)A Retórica como estudo das condições gerais do discurso suasório (argumento que diz respeito à semiologia porque, como veremos, mais uma vez está em jogo a dialética entre códigos e mensagens); 2)A Retórica como técnica gerativa, isto é, como posse de mecanismos argumentativos que permitem gerar argumentações suasórias baseadas numa dialética moderada entre informação e redundância (terreno que abrange várias disciplinas voltadas 
para o estudo dos mesmos mecanismos do pensamento e da emoção); 3)A Retórica como depósito de técnicas argumentativas já provadas e assimiladas pelo corpo social. Nesta última acepção, a retórica é um depósito de soluções codificadas, atendo-se às quais a persuasão reconfirma, com uma redundância final, os códigos de onde se origina. (Eco, 1971)

É claro que Eco se identifica com essa terceira acepção e define como retórico um raciocínio que empregue frases feitas e opiniões estabelecidas, apelos à emoção já desgastados e consumidos, mas ainda eficazes para leitores/ouvintes mais despreparados.

E a razão por se levar em conta, portanto, elementos de Retórica, como metáfora e metonímia, é a de que as HQs são essencialmente mensagens estéticas, presentes no âmbito cultural e opinativo do discurso midiático que, hoje, mais do que nunca, prioriza as técnicas de redação publicitária, por necessidade de persuadir, muito mais do que de convencer, seus leitores/consumidores.

Agregando esse conhecimento, tomam-se emprestados alguns conceitos da Retórica para constatar que o simbólico mundo do futebol, narrativizado e midiatizado, é bastante curioso, inferencialmente atrativo, quando se trata das personagens sujeitos-históricos do futebol.

Sabe-se que o processo metafórico se institui, quando o sujeito, pra designar um objeto, não o designa objetivamente, chamando-o pelo nome próprio ou comum, mas recorre a um outro campo semântico (campo de significação) para eleger um outro elemento que, em princípio, estaria totalmente fora do conjunto das qualidades essenciais que poderiam ser atribuídas àquele objeto.

Câmara Jr. (1986) pode ajudar nessa definição de Metáfora:

É a figura de linguagem que consiste na transferência de um termo para um âmbito de significação que não é o seu; não se fundamenta numa relação objetiva entre a significação própria e a figurada, mas sim, numa relação toda subjetiva, criada no trabalho mental de apreensão.

Como foi dito antes, esse âmbito de significação, que não é o seu, é o que se entende por campo semântico. A metáfora é o resultado da intersecção de dois conjuntos, esses dois conjuntos são dois campos semânticos distintos, o conjunto do mundo real e o conjunto do mundo simbólico, pois é o homem, com seu poder criativo, quem estabelece e força algo em comum entre esses dois elementos que não têm relação aparente e objetiva alguma.
É na zona de intersecção dos conjuntos que há a ocorrência da metáfora. Foi Othon Garcia (...) em Comunicação em Prosa Moderna, que apresentou o processo dessa forma, denominando-o de Teoria dos Círculos Secantes. Para reforçar ainda mais essa concepção, convém sair do âmbito da lingüística e da gramática, e passar ao campo da semiótica e suas complexidades, mostrando como Greimas (2008) concebe a metáfora:

Do âmbito da retórica, a metáfora designava uma das figuras (chamadas tropos) que 'modificam o sentido das palavras'. (...) Considerada do ponto de vista das 'estruturas de recepção', a metáfora aparece como um corpo estranho (como uma anomalia na perspectiva gerativa), cuja legibilidade permanece sempre equívoca ainda quando é garantida pelo percurso discursivo no qual se insere. (...) desligada de seu contexto, ela deve ser considerada uma figura nuclear que talvez carregue consigo, quando de sua transferência, alguns semas pertencentes ao contexto de origem.

Associando com a relação entre personagens das HQs e os sujeitos históricos que eles representam, vê-se que geralmente a motivação para a sua instauração é de ordem comparativa, isto é, esboça-se um traço semelhante e caricato ao sujeito histórico real.

Por isso, é fundamental, nesse momento, também estabelecer distinções entre a metáfora e a metonímia, outra importante figura de retórica, cujo processo de criação obedece à lógica da pertinência entre elementos de um mesmo conjunto. Conforme Câmara Jr (1986):

Figura de linguagem que consiste na ampliação do âmbito da significação de uma palavra ou expressão, partindo de uma relação objetiva entre a significação própria e a figurada. A metonímia coloca uma palavra num campo semântico que não é o seu, na base de agrupamentos onomasiológicos das coisas extralingüísticas que não coincidem com os agrupamentos semânticos das formas lingüísticas.

Essas relações objetivas, diferentes das relações subjetivas, próprias do processo metafórico, podem ser de diversas ordens: da parte pelo todo ou todo pela parte - por isso a associação com a pertinência ou continência de elementos dentro de conjuntos (oriundos da matemática), do produto pela matéria, entre autor e obra, continente por conteúdo etc.

Para complementar essa concepção de metonímia, convém novamente, sair do âmbito lingüístico e gramatical e entrar no mérito da Semiótica de Greimas: 
Tradicionalmente, a figura de retórica chamada metonímia designa o fenômeno lingüístico segundo o qual uma dada unidade frasal é substituída por outra unidade que a ela está 'ligada'. É o resultado de um procedimento de substituição pelo qual substitui um dado sema (signo) por um outro sema (outro signo), pertencentes ambos ao mesmo campo semântico. Considera-se a metonímia uma metáfora 'desviante'. Levi-Strauss não pôde deixar de assinalar que, no pensamento mítico, 'toda metáfora acaba em metonímia' e que toda metonímia é de natureza metafórica.

Se foi possível visualizar o processo metafórico a partir do diagrama matemático da intersecção de conjuntos, então o processo metonímico pode ser representado graficamente como aquela outra noção da matemática do conjunto e de seus subconjuntos.

Quando se metonimiza um termo, parte-se dessa relação cognitiva que não é mais a da comparação, mas a da substituição indireta, da vizinhança, da aproximação. Por isso, então, o processo metonímico acontece a partir desse tipo de associação, por pertinência ou continência de elementos dentro de um mesmo conjunto, ou de pequenos subconjuntos todos contidos no mesmo único conjunto, isto é, as partes de um todo maior.

É sempre importante entender a diferença das abordagens da retórica para a semiótica, já que a primeira se restringe a identificar fenômenos semânticos que ocorrem em expressões e termos isolados, no âmbito frasal, enquanto a segunda fica mais atrelada ao universo narrativo, mais abrangente, em que podem circular não apenas palavras ou enunciados, mas toda uma cadeia narrativa e figurativa.

Se entendermos a Semiótica como uma vertente filosófica no sentido de que todo o processo de interpretação de signo tende para a finalidade de se chegar à "verdade", ou seja, num processo de mudança de um estado de insatisfação para outro de satisfação, com base no conhecimento (Teixeira, 1999, p.68), então se pode definir signo como aquilo que, sob certo aspecto, representa alguma coisa para alguém, conforme os postulados de Peirce. Já Greimas apresenta uma definição de Semiótica mais restritiva e específica, considerando-a como teoria da significação.

A teoria semiótica é conhecida há bastante tempo, com o estudo de diversas correntes, mas somente a partir do século XX, especialmente com a Teoria Geral dos Signos, de Charles Sanders Peirce, que ela consagrou-se como a ciência que se conhece hoje. Peirce estabeleceu categorias através da análise de como as coisas aparecem na mente humana, criando caracteres elementares e universais, constituindo as experiências necessárias à compreensão das coisas, tanto reais, quanto fictícias.

Toda leitura é um processo de interação, e o processo é naturalmente semiótico. Toda semiose é o sistema de interpretação de passagem entre signos. A leitura acontece a partir das experiências e interpretações de signos, está sempre se construindo e depende de outros novos signos para que consiga se aperfeiçoar. Propriedades e qualidades de signos são selecionadas, e a partir deles, generalizações e reorganização de todos os signos já conhecidos e interpretados.

O discurso das HQs é representado em abordagem de interpretação imagética, carregada de significados, que são trazidos a partir de um contexto social e cultural específico, favorecendo ao leitor o desenvolvimento de linguagem, pensamento, criação e transformação. E este dispositivo é fundamentado pela imagem, que sempre acompanha a narrativa disposta em balões. A leitura da imagem é o ponto de partida para um processo de desenvolvimento e reflexão.

Nesse sentido, a semiótica desempenha papel importante na leitura, como construção, sensação e vivência por parte do leitor/torcedor, que pelo cognitivismo torna o objeto real. Assim, imagem e discurso ganham dimensão e são reconstruídos.

Santaella (1990) propõe três faculdades necessárias para se desenvolver a tarefa da fenomenologia: 1) a capacidade contemplativa, isto é, abrir as janelas do espírito e ver o que está diante dos olhos; 2) saber distinguir, discriminar resolutamente diferenças nessas observações, e 3) ser capaz de generalizar as observações em classes ou categorias abrangentes.

A leitura das HQs perpassa estas três faculdades, da contemplação da ilustração, distinção e generalização, trazendo a compreensão do todo. Então, é através da semiótica que se pode ter uma teoria de leitura de imagens. A partir da leitura das múltiplas informações imagéticas contidas nas HQs, o leitor é conduzido a um estado que a semiótica chama de primeiridade, consciência imediata, em que não há ação, é característica de espontaneidade, originalidade. As imagens percebidas na narrativa de $\mathrm{HQ}$, da qual provém a informação que o público tem sobre os jogadores sujeitos-históricos, as qualidades puras, imediatamente sentidas, são típicas da primeiridade. 
A primeiridade aparece em um estágio inicial no qual o leitor perpassa diversos estágios na leitura das HQs e a interpretação que faz acerca das imagens observadas se aperfeiçoa. Nesse estágio, o leitor observa a imagem centrada nos elementos isolados, não estabelece relação entre eles, identifica, observa e enumera. Esse estágio de observação pode elaborar uma associação de memória, relacionada ou não à imagem observada. Durante este estágio de leitura, o leitor apenas considera seu interesse, seu próprio ponto de vista.

No estágio seguinte, de secundidade, ele já começa a realizar comparações na ilustração, dando mais importância ao tema da imagem como um todo. Nessa fase, a imagem bela é aquela próxima à realidade. 0 significado está ligado não ao objeto, mas as associações que se ligam a ele. Uma imagem se torna significativa quando associada ao que representa para o leitor.

A terceiridade, próximo estágio de observação, relaciona-se com a percepção, comparação e conclusões do leitor a respeito da imagem observada. Nesta fase, é possível relacionar a ilustração aos fatos da vida, imaginando outras situações baseadas em conhecimentos previamente adquiridos. Leitura de textos escritos também são características de terceiridade.

Só a partir desta fase o leitor começa a perceber a organização de uma narrativa de HQs, e esse processo se dá a partir de sua experiência de leitura, da relação dela com a imagem, sua inserção no meio cultural e intervenções dos outros que provoquem a curiosidade pelas leituras mais aprofundadas. Consequentemente, estes aspectos ajudam a refletir a compreensão da realidade, estimulando o leitor a construir sua própria visão de mundo, e o olhar curioso, aperfeiçoado, possibilita a interação aos processos de socialização.

Não se pode esquecer que nessa relação entre conteúdo e expressão gera-se o que se conhece por efeitos estilísticos da expressão. Há textos que cumprem função utilitária como a de informar, convencer, explicar e documentar, e textos que cumprem uma função estética. As HQs cumprem ambas as funções. A utilitária, por informar e comentar sobre determinado aspecto do universo futebolístico, no qual estão inseridos os personagens sujeitos-históricos, e a estética, por apresentar estas informações comentadas de maneira estilisticamente criativa.

Se Roland Barthes diz que o mito é um sistema semiológico, essa observação autoriza a caracterização dos personagens Pelezinho, Ronaldinho Gaúcho e Neymar
Jr. como signos mitificados, pois de personagens das narrativas jornalísticas - a partir das quais obtemos informações sobre suas condições de sujeitos históricos do futebol - eles se transmutam para a condição de protagonistas ficcionais das HQs, numa condição dupla de personagem.

Verifica-se, com isso, que nas mais recentes narrativas dos personagens RG e NJ, há um profundo investimento num universo ficcional variado. São os personagens interagindo com seres extraterrestres, viajando pelo espaço, ou seja, extrapolam a verossimilhança do contexto futebolístico corriqueiro, no qual a bola é mero álibi, mero pretexto secundário. Diferente das narrativas de Pelezinho, que veiculam com mais propriedade conhecimento sobre o esporte, que problematiza mais contundentemente sobre o dia-a-dia da prática profissional e de lazer do futebol.

A narrativa das HQs de Maurício de Sousa é um conjunto de signos constituintes de um discurso, um conjunto de linguagens construtoras do texto. Em cada nova leitura, toda experiência refaz, continuamente, visões de mundo, de pessoa e de realidade.

\section{REFERÊNCIAS BIBLIOGRÁFICAS}

Barthes, R. (2001). Mitologias. $11^{\text {a }}$ ed. Rio de Janeiro: Bertrand Brasil.

Bibe-Luyten, S. (1985). O que é História em Quadrinhos. São Paulo: Brasiliense. Camara Jr., Mattoso, J. (1992). Dicionário de Lingüística e Gramática. 16ª ed. Petrópolis: Vozes.

Eco, U. (1971). A Estrutura Ausente. São Paulo: Perspectiva.

(1976). Tratado Geral de Semiótica. 2a ed. São Paulo: Perspectiva.

García, O. (1986). Comunicação em Prosa Moderna. 13a ed. FGV: Rio de Janeiro.

Greimas, A. J. (1975). Sobre o Sentido: ensaios semióticos. Petrópolis: Vozes.

Greimas, A. J. y Courtés, J. (2008). Dicionário de Semiótica. São Paulo: Contexto.

Koch, I. V. (2000). O texto e a construção de sentidos. 3. ed. São Paulo: Contexto.

Marcuschi, L. A. (2003). Gêneros Textuais: definição e funcionalidade. In Dionisio, A. (Eds.) Gêneros Textuais e Ensino. Rio de Janeiro: Lucerna. 
Peirce, C.S. (1998). Semiótica. São Paulo: Perspectiva, 1998.

Santaella, L. (1990). O que é semiótica. São Paulo: Brasilense.

(2008). Semiótica Aplicada. São Paulo: Cengage Learning.

Sousa, M. (2014). Pelezinho. Edições históricas 1 a 12. São Paulo: Panini.

(2007/2014). Ronaldinho Gaúcho. Edições 1 a 90. São Paulo: Panini. (2013/2014). Neymar Jr. Edições 1 a 14. São

Paulo: Panini.

Teixeira, C. (1999). Semiótica, Informação e Comunicação. São Paulo: Perspectiva.

Travaglia .L.C. (1998). Texto e Coerência. 4 ed. São Paulo: Cortez.

Trevisan, E. (1992). Leitura: coerência e conhecimento prévio. Santa Maria/RS: Ed. da UFSM. 